\title{
Increased $\beta$-Lactoglobulin Absorption during Rotavirus Enteritis in Infants: Relationship to Sugar Permeability
}

\author{
TAINA JALONEN, ERIKA ISOLAURI, MARTINE HEYMAN, ANNE-MARIE CRAIN-DENOYELLE, \\ PEKKA SILLANAUKEE, AND TIMO KOIVULA \\ Department of Clinical Sciences, University of Tampere, Tampere, Finland [T.J., E.I.]; INSERM U 290, \\ Hopital Saint-Lazare, Paris, France [M.H., A-M.C.-D.]; and Department of Clinical Chemistry, \\ Tampere University Hospital, Tampere, Finland [P.S., T.K.]
}

\begin{abstract}
We studied absorption of the potentially allergenic protein $\beta$-lactoglobulin during acute rotavirus diarrhea in infants and assessed the relationship of this macromolecular absorption with intestinal sugar permeability. After oral rehydration, 38 patients with acute gastroenteritis were given orally a 100 -ml solution containing $4 \mathrm{~g}(11.7 \mathrm{mmol} / \mathrm{L})$ of lactulose and $0.8 \mathrm{~g}(4.4 \mathrm{mmol} / \mathrm{L})$ of mannitol, and their recovery rate as shown in urine passed during the subsequent $5 \mathrm{~h}$ was measured. A blood sample was taken $2 \mathrm{~h}$ after a milk feed for ELISA measurement of $\beta$-lactoglobulin in circulating immune complexes. Twelve nondiarrhea patients were studied after an overnight fast as controls. Immune complexes containing $\beta$-lactoglobulin were found in the serum of all, but the levels [median (range)] were significantly higher in patients with rotavirus diarrhea [686 (36-4352)] than in nondiarrhea patients [165 $(0-2594)] ; p=0.007$. The mean $(95 \%$ confidence interval) lactulose/mannitol urinary recovery ratios were increased in patients with acute diarrhea $[0.19(0.10,0.30)]$ compared to nondiarrhea patients $[0.01(0.005,0.02)] ; p=0.0001$ Thus, a significant correlation between $\beta$-lactoglobulin absorption and sugar permeability was found; Spearman's rank correlation coefficient $=0.42, p=0.004$. This correlation was not, however, direct but was due to an inverse relationship between urinary recovery of mannitol and serum $\beta$-lactoglobulin immune complexes. These results indicate that rotavirus gastroenteritis is associated with enhanced $\beta$-lactoglobulin absorption and elevated lactulose/mannitol permeability test results, but these represent different phenomena. (Pediatr Res 30: 290-293, 1991)
\end{abstract}

\section{Abbreviations}

\section{CI, confidence intervals}

After birth, the maturation of the human gastrointestinal tract includes development of a mucosal barrier that selectively prevents a variety of potentially antigenic or toxic substances from entering the internal environment of the body. Although at birth highly impermeable to macromolecules, the gut has specialized transport mechanisms for these substances in the Peyer's patches and the villous epithelium (1). Thus even under physiologic conditions, antigenically active food proteins or their peptide fragments are absorbed and gain access to the immune systems

Received November 21, 1990; accepted April 15, 1991

Correspondence and reprint requests: Dr. Erika Isolauri, Department of Clinica Sciences, University of Tampere, Teiskontie 35, 33520 Tampere, Finland. of the body (2). In various pathologic conditions, such as animal models of viral gastroenteritis $(3,4)$, antigenic macromolecular absorption is increased, which raises the question of possible local or systemic sensitization. There is no direct evidence of such increased intestinal permeability to proteins in human infants. This reflects the difficulty of measuring intestinal permeability to macromolecules by noninvasive methods. Most often, gastrointestinal permeability is measured via probe molecules like mannitol and lactulose. Such dual sugar absorption tests have been recommended in clinical practice as the most appropriate means to measure intestinal integrity (5). However, there is no direct evidence to indicate that the sugar permeability tests also measure the absorption of macromolecules. Recent studies on animal models suggest that no such simple correlation exists (6). Therefore, the applications of the sugar permeability tests remain elusive.

The purpose of the present study was to evaluate intestinal permeability to the potentially allergenic protein $\beta$-lactoglobulin during rotavirus enteritis in infants and to evaluate the relationship of this macromolecular absorption to intestinal sugar permeability. For this purpose, we measured the absorption of dietary $\beta$-lactoglobulin and simultaneously related this to lactulose/ mannitol urinary recovery ratios in infants with rotavirus diarrhea and in patients with no evidence of acute infection.

\section{MATERIALS AND METHODS}

Patients. Fifty children, 1 to 36 mo (mean age $12.4 \mathrm{mo}$ ) of age, were studied. The study population included two groups of patients: children with acute gastroenteritis and those with no evidence of acute infection. In these patients the absorption of dietary $\beta$-lactoglobulin and the urinary recovery ratios of lactulose/mannitol were simultaneously measured to correlate the results of the permeability tests in different clinical conditions.

Acute gastroenteritis. Thirty-eight patients, mean age 13.5 (SD, 6.2) mo, were admitted for treatment of acute diarrhea during a rotavirus epidemic. The mean duration of diarrhea at home was 2.9 (SD, 1.4) d. Rotavirus antigen (Rotazyme, Abbott Laboratories) was demonstrated in stools in $84 \%$ of the cases. Bacterial cultures for Salmonella, Yersinia, Campylobacter, and Shigella were negative in all. The treatment of the patients followed standard clinical practice. Oral rehydration was accomplished in $6 \mathrm{~h}$ with a solution containing $\mathrm{Na}^{+} 60 \mathrm{mmol} / \mathrm{L}$ and glucose 144 $\mathrm{mmol} / \mathrm{L}$ given at twice the estimated fluid deficit (7). After rehydration, normal full feedings appropriate for age were reintroduced, including milk and milk products. Patients who were not receiving cow's milk were excluded.

The intestinal permeability test was performed within the first $12 \mathrm{~h}$ in hospital. At this time $87 \%$ of the patients passed diarrheal stools. After initial fluid therapy, a $100-\mathrm{mL}$ solution containing 
$4 \mathrm{~g}(11.7 \mathrm{mmol} / \mathrm{L})$ of lactulose and $0.8 \mathrm{~g}(4.4 \mathrm{mmol} / \mathrm{L})$ of mannitol $\left(227 \mathrm{mosmol} / \mathrm{kg} \mathrm{H}_{2} \mathrm{O}\right)$ was given orally. All urine passed during $5 \mathrm{~h}$ was collected and measured, and an aliquot was immediately frozen and kept at $-20^{\circ} \mathrm{C}$ until analysis. Also within the first $12 \mathrm{~h}$ in the hospital, a blood sample was taken 2 $\mathrm{h}$ after a milk feed $(10 \mathrm{~mL} / \mathrm{kg}$ body weight $)$ in conjunction with routine assays for measurement of $\beta$-lactoglobulin concentration. Serum was then separated and stored at $-20^{\circ} \mathrm{C}$ until analysis.

Nondiarrhea patients. Nondiarrhea patients included 12 children of mean age 9.0 (SD, 8.4) mo. These were electively admitted for examinations unrelated to the gastrointestinal tract (nine); for a jejunal biopsy, which was found normal (one); and for a diagnostic cow's milk challenge test, which was negative (two).

The lactulose/mannitol permeability test was done after an overnight fast of at least $6 \mathrm{~h}$. Within $12 \mathrm{~h}$ of the urine collection, a venous blood sample was drawn $2 \mathrm{~h}$ after milk ingestion (10 $\mathrm{mL} / \mathrm{kg}$ body weight) for the analysis of serum $\beta$-lactoglobulin concentration.

Informed consent was obtained from the children's parents, and the study was approved by the Hospital's Committee on Ethical Practice.

Lactulose/mannitol permeability test. For lactulose and mannitol gas-liquid chromatography determination, a Shimadzu GC14A Gas Chromatograph and a Shimadzu C-R5A integrator were used (Shimadzu Corporation, Kyoto, Japan) with the CPSil 5 CB capillary column (Chrompack, Middelburg, The Netherlands). The sugar alcohols, lactulose, mannitol, and inositol, were purchased from Sigma (Sigma Chemical Company, St. Louis, MO).

One $\mathrm{mL}(0.5 \mathrm{mmol} / \mathrm{L})$ of inositol as an internal standard and $1.0 \mathrm{~mL}$ of Duolite MB 5113 mixed resin (BHD Chemicals Ltd., Poole, England) as desalt were added to $1.0 \mathrm{~mL}$ of urine. The samples were shaken, centrifuged at $2000 \times g$ for $10 \mathrm{~min}$, and the supernatant transferred to a glass tube to dry under a stream of air at $60^{\circ} \mathrm{C}$. The sugars were derivatized according to Sweeley et al. (8) and Laker and Mount (9) by trimethylsilylation using Tri-Sil reagent (Pierce, Pierce Chemicals Company, Rockford, IL). After the addition of $200 \mu \mathrm{L}$ silylating reagent, the glass tube was closed and placed in an incubating oven $\left(60^{\circ} \mathrm{C}\right)$ for $10 \mathrm{~min}$. The derivatized sugars were separated by means of temperature programming from $180^{\circ} \mathrm{C}$ at $1 \mathrm{~min}$ to $260^{\circ} \mathrm{C}$ at $30^{\circ} \mathrm{C} / \mathrm{min}$, with the upper temperature maintained until the lactulose peak emerged. The total analysis time was $6.7 \mathrm{~min}$. The peaks were quantitated by peak-height measurement. The total amount of lactulose or mannitol was calculated by substracting the starting level from the 5-h collection level.

The urinary mannitol concentration before the permeability test has been previously found to be insignificant (7).

Mannitol is a hexitol but for convenience is designated as "sugar" in the present report.

Detection of $\beta$-lactoglobulin in circulating immune complexes. In a first set of assays, free $\beta$-lactoglobulin was assayed in serum samples, as previously described, by double sandwich ELISA (10). Despite the high detection level of this assay $(1 \mathrm{ng} / \mathrm{mL})$, no free $\beta$-lactoglobulin was detectable in any sera. It was thus concluded that $\beta$-lactoglobulin was probably present in sera in immune-complexed form.

The immune complexes were titered as follows: antisera to $\beta$ lactoglobulin were raised by s.c. injection of rats with $3 \mathrm{mg} \beta$ lactoglobulin in $0.5 \mathrm{~mL}$ saline solution emulsified with $0.5 \mathrm{~mL}$ Freund's complete adjuvant. Three weeks later, the same injections were repeated once daily for 3 consecutive days. Five days after the final injection, the animals were exsanguinated and sera stored at $-80^{\circ} \mathrm{C}$ until use. The specificity of the serum was tested by titration in the presence of different milk proteins ( $\beta$-lactoglobulin, $\alpha$-lactalbumin, BSA and casein). Antibodies were mainly detected against $\beta$-lactoglobulin inasmuch as titers were at least 20 times greater than for the other milk proteins. Microtiter plates (Nunc, Polylabo, Paris, France) were then coated for
$4 \mathrm{~h}$ at $37^{\circ} \mathrm{C}$ with $100 \mu \mathrm{L}$ per well of rat $\beta$-lactoglobulin antiserum diluted 1:700 in $0.01 \mathrm{M}$ carbonate buffer $\mathrm{pH}$ 9.6. The plates were washed with PBS-0.05\% Tween pH 7.4 and shaken dry. A total of $100 \mu \mathrm{L}$ of $1 \%$ gelatin (Prolabo, France) was added to each well, and plates were stored overnight at $4^{\circ} \mathrm{C}$. The plates were then washed, and $100 \mu \mathrm{L}$ of serial half-dilutions of sera were added to each well and incubated for $1.5 \mathrm{~h}$ at $37^{\circ} \mathrm{C}$. After additional washing of the plates, $100 \mu \mathrm{L}$ of goat anti-human IgA (or $\mathrm{E}, \mathrm{G}, \mathrm{M}$ ) Fc peroxidase conjugate diluted $1: 1000$ in PBSTween was added and incubated for $2 \mathrm{~h}$ at $37^{\circ} \mathrm{C}$. The plates were again washed and peroxidase assayed by staining with $0.4 \mathrm{mg} /$ $\mathrm{mL}$ diamino-orthopenylene in $0.05 \mathrm{M}$ citrate buffer $\mathrm{pH} 4.0$ containing $0.1 \% \mathrm{H}_{2} \mathrm{O}_{2}$. The staining was developed in the dark with external stirring at $37^{\circ} \mathrm{C}$ for $20 \mathrm{~min}$. The reaction was stopped with $6 \mathrm{~N} \mathrm{H}_{2} \mathrm{SO}_{4}$ and the absorbance measured at 492 $\mathrm{nm}$ with a Uniskan plate reader (Flow Laboratories, McLean, VA). Titers were expressed as the highest dilution giving a signal above the background.

Statistical analysis. Logarithmic transformations were applied because of skewed distributions in urinary recovery of the test markers. These are presented as geometric means with $95 \% \mathrm{CI}$, and two-tailed independent $t$ test was used to determine the statistical significance of the differences. The $\chi^{2}$ test was used when comparing proportions. Titers of circulating immune complexes containing $\beta$-lactoglobulin are not continuous variables; therefore the statistical calculations using these measurements were nonparametric. Spearman's rank correlation coefficient was applied to determine the degree and significance of association between titers of serum immune complexes and urinary lactulose/mannitol recovery ratios (with no transformation). The Mann-Whitney $U$ test was used when comparing various groups.

\section{RESULTS}

Determination of $\beta$-lactoglobulin in immune complexes in patients with acute gastroenteritis and in nondiarrhea patients. No free $\beta$-lactoglobulin was detected in any serum tested. All patients had normal serum IgG, IgM, and IgA levels. Immune complexes containing $\beta$-lactoglobulin were found in the serum of all patients $2 \mathrm{~h}$ after milk ingestion, but the levels were significantly higher in patients with acute gastroenteritis than in nondiarrhea patients (Table 1 ). The difference was mainly caused by a rise in the amount of IgM-type immune complexes in patients with acute diarrhea.

Lactulose/mannitol urinary recovery ratios in patients with

Table 1. $\beta$-lactoglobulin in circulating immune complexes in patients with acute gastroenteritis and in nondiarrhea patients

\begin{tabular}{cccc}
\hline $\begin{array}{c}\text { Immune complexes } \\
\text { (titer)* containing } \\
\beta \text {-lactoglobulin }\end{array}$ & $\begin{array}{c}\text { Acute } \\
\text { gastroenteritis } \\
(n=38)\end{array}$ & $\begin{array}{c}\text { Nondiarrhea } \\
\text { patients } \\
(n=12)\end{array}$ & $\begin{array}{c}\text { Mann-Whitney } \\
U \text { test }\end{array}$ \\
\hline IgA & & & \\
Median & 16 & 16 & $z=0.06$ \\
Range & $0-256$ & $0-512$ & $p=0.95$ \\
IgE & & & \\
Median & 2 & 1 & $z=0.46$ \\
Range & $0-16$ & $0-32$ & $p=0.65$ \\
IgG & & & \\
Median & 256 & 128 & $z=1.75$ \\
Range & $0-2048$ & $0-2048$ & $p=0.08$ \\
IgM & & & \\
Median & 256 & 5 & $z=4.13$ \\
Range & $0-2048$ & $0-128$ & $p=0.0001$ \\
Total $\dagger$ & & & \\
Median & 686 & 165 & $z=2.70$ \\
Range & $36-4352$ & $0-2594$ & $p=0.007$ \\
\hline
\end{tabular}

* Measured by ELISA, titer expressed as the highest dilution giving a signal above background.

$\uparrow$ Sum of the titers of different Ig isotypes. 
acute gastroenteritis and in nondiarrhea patients. The lactulose/ mannitol urinary recovery ratios were elevated in most of the diarrhea patients, only four out of 38 of them having normal lactulose/mannitol excretion ratios. The final diagnosis of the one nondiarrhea patient with an elevated lactulose/mannitol ratio was diencephalic tumor.

The rise in the lactulose/mannitol urinary recovery ratio was found to be due to a concomitant decrease in the urinary excretion of mannitol and an increase in the excretion of lactulose (Table 2). The disciminating capacity of the ratio of the two probes was greater than that of mannitol or lactulose alone.

Relationship between absorption of $\beta$-lactoglobulin and urinary excretion of mannitol and lactulose. The total amount of circulating immune complexes containing $\beta$-lactoglobulin was significantly higher in patients with altered sugar permeability findings. The correlation between $\beta$-lactoglobulin immune complexes and sugar permeability was found to be statistically significant; Spearman's rank correlation coefficient $=0.42, p=0.004$ (Table 3). This was caused by a significant correlation between the levels of $\beta$-lactoglobulin in immune complexes of $\mathrm{IgG}$ and $\operatorname{IgM}$ isotype and the lactulose/mannitol ratios.

To establish whether this was caused predominantly by one of the sugar probes, the amount of $\beta$-lactoglobulin uptake was separately related to the urinary excretion of lactulose and mannitol (Table 3). The relationship between $\beta$-lactoglobulin immune complexes and urinary excretion of lactulose was found to be less obvious than that of the lactulose/mannitol ratio, and it failed to reach statistical significance. By contrast, urinary recovery of mannitol was inversely correlated with the amount of $\beta$-lactoglobulin absorbed.

\section{DISCUSSION}

The present results indicate that infants with rotavirus gastroenteritis have an increased absorption of the milk protein $\beta$ lactoglobulin and that this protein circulates in serum in the form of immune complexes. The results further confirm that sugar permeability is altered in such a pathologic state, but they

Table 2. Lactulose/mannitol recovery ratios in urine from patients with acute gastroenteritis and nondiarrhea patients

\begin{tabular}{lccc}
\hline & $\begin{array}{c}\text { Acute } \\
\text { gastroenteritis } \\
(n=38)\end{array}$ & $\begin{array}{c}\text { Nondiarrhea } \\
\text { patients } \\
(n=12)\end{array}$ & $\begin{array}{c}\text { Statistical } \\
\text { value }\end{array}$ \\
\hline $\begin{array}{l}\text { Lactulose/mannitol ratio } \\
\text { Mean }\end{array}$ & 0.19 & 0.01 & $t=6.92$ \\
95\% CI & $0.10,0.30$ & $0.005,0.02$ & $p=0.0001$ \\
Man \% & & & \\
Mean & 0.73 & 3.67 & $t=3.75$ \\
95\% CI & $0.46,1.17$ & $2.20,6.10$ & $p=0.0005$ \\
Lact \% & & & \\
Mean & 0.16 & 0.04 & $t=3.28$ \\
95\% CI & $0.09,0.24$ & $0.01,0.11$ & $p=0.002$ \\
\hline
\end{tabular}

do not indicate a direct correlation between intestinal transport of sugar and protein.

It is widely recognized that dual sugar permeability tests are useful in detecting an enhanced intestinal permeability that may have pathologic significance in several gastrointestinal or systemic disease states $(3,4,11)$. Even though the diagnosis of smallintestinal enteropathy is based on jejunal biopsy, noninvasive screening tests for such pathology have aroused clinical interest. On the other hand, suggestions that normal histology does not necessarily exclude increased endocytic activity to antigenic macromolecules have prompted much scientific debate on intestinal permeability test $(12,13)$. Among these, the dual sugar absorption test using lactulose and mannitol as probes has been in extensive use (14). The urinary recovery ratio of lactulose and mannitol reflects the quantity absorbed across the small-intestinal mucosa.

In villous atrophy, the diminished absorptive area leads to a decrease in the number of "aqueous pores" incorporated in the membrane structure. Reduced absorption of mannitol would detect changes in this transcellular pathway (5). Lactulose, on the other hand, is considered unable to be transported across healthy enterocytes (14). The urinary excretion ratio between higher and lower molecular weight sugars has been shown to be altered in different disease states, including villous atrophy (14), celiac disease (15), Crohn's disease, and acute gastroenteritis (7, $14,16)$. Use of such sugar permeability tests for testing intestinal permeability to macromolecules or food proteins is questionable.

The absorption of antigens has been assumed to be related in particular to urinary recovery of lactulose, which would indicate increased leakage through paracellular channels $(5,14)$. Our results, consistent with those of a previous study on neonatal guinea pigs (6), suggest that no such correlation exists. Instead, we found that patients with elevated lactulose/mannitol urinary recovery ratios showed increased macromolecular absorption. Our results do not indicate, however, a direct correlation between the two measurements. Rather, the sugar and protein uptakes across the intestinal membrane seem to be distinct processes. These suggestions are compatible with those of Turner et al. (17), who measured simultaneously bystander-protein uptake and changes in intestinal permeability to sugars in rats evincing local hypersensitivity reactions. These authors observed enhanced protein uptake in association with an increased lactulose/rhamnose excretion ratio, although no correlation between the two measurements could be demonstrated.

The finding that mannitol excretion was inversely correlated with macromolecular absorption suggests that villus atrophy or microvillous effacing lesions may be related to changes in brush border membrane composition, and to fluidity or cytoskeletal modifications leading to increased protein binding and to a higher rate of endocytic activity. The fact that mannitol excretion is decreased in gastroenteritis suggests that tight junctions are not disrupted but that the surface area available for absorption is diminished, probably due to villous abrasion. Such a villous atrophy could also have changed the proportion of immature cells in the intestinal epithelium, thus leading to increased en-

Table 3. Comparison between $\beta$-lactoglobulin absorption and urinary excretion of test markers, lactulose/mannitol ratio, mannitol, and lactulose

\begin{tabular}{|c|c|c|c|c|c|c|c|c|c|c|}
\hline \multirow{3}{*}{$\begin{array}{c}\text { Urinary } \\
\text { test markers }\end{array}$} & \multicolumn{10}{|c|}{ Immune complexes of different isotypes containing $\beta$-lactoglobulin } \\
\hline & \multicolumn{2}{|c|}{$\operatorname{IgA}$} & \multicolumn{2}{|c|}{$\operatorname{IgE}$} & \multicolumn{2}{|c|}{$\operatorname{IgG}$} & \multicolumn{2}{|c|}{ IgM } & \multicolumn{2}{|c|}{ Total $\uparrow$} \\
\hline & rho* & $p$ & rho & $p$ & rho & $p$ & rho & $p$ & rho & $p$ \\
\hline Lactulose/mannitol ratio & 0.14 & 0.34 & 0.12 & 0.40 & 0.30 & $0.04 \ddagger$ & 0.56 & $0.0001 \ddagger$ & 0.42 & $0.004 \ddagger$ \\
\hline Mannitol (\%) & -0.32 & $0.03 \ddagger$ & -0.28 & 0.06 & -0.34 & $0.02 \ddagger$ & -0.43 & $0.004 \ddagger$ & -0.46 & $0.002 \ddagger$ \\
\hline Lactulose $(\%)$ & -0.11 & 0.44 & -0.14 & 0.34 & 0.02 & $0.87^{\circ}$ & 0.26 & 0.07 & 0.08 & 0.61 \\
\hline
\end{tabular}

* Spearman's rank correlation coefficient.

$\dagger$ Sum of the titers of different Ig isotypes.

$\ddagger$ Statistically significant correlation. 
docytotic activity (18) and increased $\beta$-lactoglobulin absorption. Therefore, the rise in protein uptake could be explained by an increase in transcellular absorption.

Antigenic macromolecules such as $\beta$-lactoglobulin and ovalbumin have also been used as probes for macromolecular absorption. These methods have limitations that could account for the contradictory results obtained (19). Quantitative differences in serum antigen concentrations could be due to inhibition by antibodies present in the serum. Food antigens absorbed into the circulation across the mucosa are likely to be combined with serum antibodies with different clearance and immunopathologic consequences, depending on the type of complexes formed (20). The presence of such circulating immune complexes seems to be a constant finding in infancy, probably because of the higher antibody levels observed in childhood $(21,22)$. In the present study, it was interesting to note that in children with rotavirus diarrhea these were mainly of the IgM isotype. Our finding is in keeping with previous work on gut local immune response to rotavirus infection in children showing an IgM response to the infecting agent (Kaila $M$, Isolauri $E$, Virtanen $E$, Arvilommi $\mathrm{H}$, unpublished experiments), whereas in adults during acute gastroenteritis the response is predominantly IgA (23). These results indicate that the human intestinal secretory IgA system is not fully developed until the second year of life and that IgM compensates for it.

The level of $\beta$-lactoglobulin immune complexes in the present study was measured $2 \mathrm{~h}$ after milk feeding and is likely to quantitate the fraction of protein absorbed by the gastrointestinal epithelium. The rise in circulating immune complexes reflects an increase in the absorption of $\beta$-lactoglobulin.

Our data indicate that the enhanced absorption of macromolecules observed in different animal models of acute gastroenteritis is also relevant in the case of human infants. Indeed, in previous work on rotavirus-infected mice (4) and rabbits infected with Escherichia coli strain RDEC-1 (24), increased in vitro absorption of horseradish peroxidase was observed during the peak phase of acute diarrhea. In these experiments, the rise in horseradish peroxidase absorption was due to an increase in transcellular absorption of intact and degraded protein.

Taken together, our results suggest that the morphologic and functional alterations observed in the small-intestinal epithelium during acute gastroenteritis are associated with enhanced $\beta$ lactoglobulin absorption and elevated lactulose/mannitol permeability test results. Although macromolecular absorption and the dual sugar permeability test were shown to vary in the same way, these alterations occur by distinct processes and therefore represent different phenomena.

\section{REFERENCES}

1. Ducroc R, Heyman M, Beaufrère B, Morgat JL, Desjeux JF 1983 Horseradish peroxidase transport across rabbit jejunum and Peyer's patches in vitro. Am J Physiol 245:G54-58
2. Walker WA 1986 Allergen absorption in the intestine: implications of food allergy in infants. J Allergy Clin lmmunol 78:1003-1009

3. Keljo DJ, Butler DG, Hamilton JR 1985 Altered jejunal permeability to macromolecules during viral enteritis in the piglet. Gastroenterology 88:9981004

4. Heyman M, Corthier G, Petit A, Meslin JC, Moreau C, Desjeux JF 1987 Intestinal absorption of macromolecules during viral enteritis: an experimental study on rotavirus-infected conventional and germ-free mice. Pediatr Res $22: 72-78$

5. Anonymous 1985 Intestinal permeability. [editorial]. Lancet 1:256-258

6. Weaver LT, Coombs RRA 1988 Does 'sugar' permeability reflect macromolecular absorption? A comparison of the gastro-intestinal uptake of lactulose and beta-lactoglobulin in the neonatal guinea pig. Int Arch Allergy Appl lmmunol 85:133-135

7. Isolauri E, Juntunen M, Wiren S, Vuorinen P, Koivula T 1989 Intestinal permeability changes in acute gastroenteritis: effects of clinical factors and nutritional management. J Pediatr Gastroenterol Nutr 8:466-473

8. Sweeley C, Bentley R, Makita M, Wells W 1963 Gas-liquid chromatography of sugars and related substances. J Am Chem Soc 85:2497-2507

9. Laker M, Mount J 1980 Mannitol estimation in biological fluids by gas-liquid chromatography of trimethylsilyl derivates. Clin Chem 26:441-443

10. Gotteland M, Isolauri E, Heyman M, Tomé D, Desjeux JF 1989 Antigen absorption in bacterial diarrhea: in vivo intestinal transport of beta-lactoglobulin in rabbits infected with the enteroadherent Escherichia coli strain RDEC-1. Pediatr Res 26:237-240

11. Fagiolo U, Paganelli R, Ossi E, Quinti 1, Cancian M, D’Offizi GP, liocco U 1989 Intestinal permeability and antigen absorption in rheumatoid arthritis. Effects of acetylsalicylic acid and sodium cromoglycate. Int Arch Allergy Appl Immunol 89:98-102

12. Heyman M, Grasset E, Ducroc R, Desjeux JF 1988 Antigen absorption by jejunal epithelium of children with cow's milk allergy. Pediatr Res 24:197202

13. Strobel S, Brydon WG, Ferguson A 1984 Cellobiose/mannitol sugar permeability test complements biopsy histopathology in clinical investigation of the jejunum. Gut 25:1241-1246

14. Ford RPK, Menzies IS, Phillips AD, Walker-Smith JA, Turner MW 1985 Intestinal sugar permeability: relationship to diarrhoeal disease and small bowel morphology. J Pediatr Gastroenterol Nutr 4:568-574

15. Nathavitharana KA, Lloyd DR, Raafat F, Brown GA, McNeish AS 1988 Urinary mannitol: lactulose excretion ratios and jejunal structure. Arch Dis Child 63:1054-1059

16. Murphy MS, Eastham EJ, Nelson R, Pearson ADJ, Laker MF 1989 Intestinal permeability in Crohn's disease. Arch Dis Child 64:321-325

17. Turner MW, Boulton P, Shields JG, Strobel S, Gibson S, Miller HRP, Levinsky RJ 1988 Intestinal hypersensitivity reactions in the rat. l. Uptake of intact protein, permeability to sugars and their correlation with mucosal mast-cell activation. Immunology 63:119-124

18. Heyman M, Crain-Denoyelle AM, Desjeux JF 1989 Endocytosis and processing of proteins by isolated villus and crypt cells of the mouse small intestine. J Pediatr Gastoenterol Nutr 9:238-245

19. Powell GK, McDonald PJ, van Sickle GJ, Goldblum RM 1989 Absorption of food protein antigen in infants with food protein-induced enterocolitis. Dig Dis Sci 34:781-788

20. Paganelli R, Cavagni G, Pallone $F 1986$ The role of antigenic absorption and circulating immune complexes in food allergy. Ann Allergy 57:330-336

21. Husby S, Foged N, Høst A, Svehag SE 1987 Passage of dietary antigens into the blood of children with coeliac disease. Quantification and size distribution of absorbed antigens. Gut 28;1062-1072

22. Cunningham-Rundles C 1987 Failure of antigen exclusion. In: Brostoff $J$, Gallacombe SJ (eds) Food Allergy and Intolerance. Baillière Tindall, London, pp 223-236

23. Kantele A, Takanen R, Arvilommi H 1988 Immune response to acute diarrhea seen as circulating antibody-secreting cells. J Infect Dis 158:1011-1015

24. Isolauri E, Gotteland M, Heyman M, Pochart P, Desjeux JF 1990 Antigen absorption in rabbit bacterial diarrhea (RDEC-1). In vitro modifications in ileum and Peyer's patches. Dig Dis Sci 35:360-366 